\title{
Multiwall Carbon Nanotube - Epoxy Composites with High Shielding Effectiveness for Aeronautic Applications
}

\author{
Aidin Mehdipour, Member, IEEE, Iosif D. Rosca, Christopher W. Trueman, Senior Member, IEEE, \\ Abdel-Razik Sebak, Fellow, IEEE, and Suong. V. Hoa
}

\begin{abstract}
Using mass-produced multiwall carbon nanotubes (MWCNTs) from different providers, we have fabricated nanocomposites with high and nearly constant shielding effectiveness (SE) over a wide frequency range, up to $26.5 \mathrm{GHz}$. The MWCNT weight fraction and sample thickness were lower than $10 \%$ and $2 \mathrm{~mm}$, respectively. The fabrication process and percolation curves are described. A high D.C. conductivity of 239.1 S/m was achieved at a MWCNT loading of only $8 \%$ by weight. The effect of aspect ratio on shielding performance is addressed as well. By comparing the measured $\mathrm{SE}$ of the composite with predictions from a model of the measurement setup using Microwave Studio, the effective conductivity of the nanocomposite was determined. Since the thickness of sample is very important for shielding analysis, the SE/unit thickness diagram was calculated by using the effective parameters of samples. The results were verified experimentally by measuring the SE of samples with different thicknesses.
\end{abstract}

Index Terms - Nanocomposites, multiwall carbon nanotubes, shielding effectiveness, electrical conductivity, waveguides.

\section{INTRODUCTION}

L IGHTWEIGHT and highly conductive composite

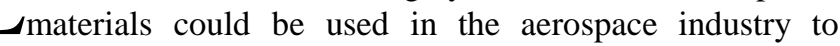
replace metal for an aircraft skin and still provide effective shielding against electromagnetic interference (EMI).

Composite materials are increasingly used in aircraft and associated applications due to their light weight, high strength, high stiffness and good fatigue resistance. Recent

Manuscript received $* * * * * *$. This work was supported in part by the Natural Sciences and Engineering Research Council of Canada (NSERC), Bell Helicopter Textron Canada Ltd., Delastek Ltd. and Consortium for Research an Innovation in Aerospace in Quebec (CRIAQ).

A. Mehdipour was with the Department of Electrical and Computer Engineering, Concordia University, Montreal Quebec, H3G 2W1, Canada. He is now with INRS, University of Quebec, Montreal, QC H3C 3J7, Canada (e-mail:mehdipour@emt.inrs.ca).

C. W. Trueman and A. R. Sebak are with the Department of Electrical and Computer Engineering, Concordia University, Montreal Quebec H3G 2W1 Canada. A. R. Sebak is also with PSATRI, King Saud University, Riyadh 11451, KSA. (email: trueman@ece.concordia.ca, abdo@ece.concordia.ca).

I. D. Rosca and S. V. Hoa are with the Department of Mechanical and Industrial Engineering, Concordia University, and with the Concordia Center for Composites (CONCOM), Montreal, Quebec, H3G, 2W1 Canada, (email: rosca_iosif@yahoo.com, hoasuon@alcor.concordia.ca) developments of new techniques for manufacturing also make them to be cost competitive to metallic counterparts $[1,2]$. Commonly used composite materials are made of epoxy matrix and carbon fibers. Airplanes such as Boeing 787 and Airbus 380 have about $50 \%$ of their structures made of composite materials.

High electrical conductivity and high aspect ratio (AR) make carbon nanotubes (CNTs) one of the most promising filler materials for conductive polymer nanocomposites [3][22]. Recently, due to high conductivity and outstanding mechanical properties, CNT composite has been also used as an efficient replacement of copper in antenna applications [23]-[25]. Because of their low price and scalable production, multiwall carbon nanotubes (MWCNTs) are extensively used with epoxy resins, one of the most widely used thermosets, to obtain conductive composites [3]. The conductivity of the composite and its shielding effectiveness (SE) are determined by the properties and loading of the CNTs, and by the characteristics of the conductive network formed by the CNTs throughout the matrix. To obtain a conductive network, highlyentangled agglomerates of MWCNTs have to be dispersed efficiently into the resin by shear mixing or by ultrasonic processing. Among the shear mixing techniques, three-roll milling [4-7] is one of the best methods as it is solvent free, scalable, uniformly shears the entire volume of the material, and can easily handle high nanotube loadings.

The aspect ratio of the nanotubes is one of the main parameters that determines their percolation behavior and as a result, the conductivity $[3,8-10]$ of the nanocomposites.

The majority of the studies on nanocomposites made of CNTs and thermoplastics [11-18] or thermosets [19-22] have reported the shielding effectiveness to be up to $60 \mathrm{~dB}$ over various frequency ranges, from low frequencies $(130 \mathrm{MHz})$ up to the K-band where the maximum SE of 20 to $60 \mathrm{~dB}$ is achieved only at very high nanotube loadings (15 to $50 \mathrm{wt} \%$ ). However, high CNT loading (>10wt\%) is detrimental to the process and cost of the composite.

Recently at the Concordia Center for Composites (CONCOM) [26], we have produced highly conductive nanocomposites made of mass-produced MWCNTs at low loadings $(<10 w t \%)$ and epoxy resin [27]. The dispersion of MWCNTs was carried out by three-roll milling. However, in 
order to use composites in the aeronautic applications, the high frequency study on shielding properties is an issue to be addressed.

In this work, first we briefly introduce the preparation process and DC conductivity properties of the proposed highly conductive nanocomposites. Then, the high shielding performance of various samples over G-, X-, Ku- and K-band frequency range is investigated and compared with SE of other types of CNT samples reported in the literature. In addition to the conductivity, the thickness of the sample determines the SE as well. The effect of sample thickness on the SE of our nanocomposites is assessed and verified experimentally.

\section{SAMPle PREParation AND PERCOlation CURVES}

\section{A. Materials}

MWCNTs synthesized by catalytic vapor deposition were produced by Arkema (Graphistrength-C100), Bayer Material Science (Baytubes-C150P) and NanoLab (Industrial Grade CNTs-NLIG). Their main characteristics, given by the manufacturer, are presented in Table I. The epoxy resin Epon 862 and the curing agent Epikure W were produced by Hexion Specialty Chemicals. The MWCNTs and all the reagents were used as received.

\section{B. Length and diameter measurement of the MWCNTs}

The length and diameter of the MWCNTs were measured using a Hitachi 4700 scanning electron microscope (SEM) at 2 $\mathrm{kV}$ of accelerating voltage and $10 \mu \mathrm{A}$ of current intensity. Approximately $2 \mathrm{mg}$ of MWCNTs were dispersed by a tip sonicator (Misonix 3000) at the minimum power for $4 \mathrm{~min}$. in $20 \mathrm{~mL}$ of deionized water containing $0.1 \mathrm{wt} \%$ of Triton-X100 (Sigma Aldrich). Next, an SEM stub was dip-coated with the nanotube suspension and dried at room temperature. The magnification used for imaging was from $15 \mathrm{k}$ up to $25 \mathrm{k}$ for the length measurement and $60 \mathrm{k}$ for the diameter measurement. Using the ImageJ $1.40 \mathrm{~g}$ software, we measured 500 lengths and 250 diameters for each MWCNT assortment.

Table II presents the minimum, maximum and average values of the length and diameter for each MWCNT assortment. The average diameters of the MWCNTs are quite close, and agree well with those given by the manufacturer, shown in Table I. In the case of length, Table II shows large discrepancies between the measured data and the manufacturer's specification. While the maximum length given by the manufacturer is similar to the measured value, the minimum length is usually much greater than the measured value. Furthermore, the average lengths of the nanotubes are very close to the minimum presented by the manufacturer (C100) or even lower than the minimum (NLIG, and C150P). This is the main reason that the mean aspect ratio in Table II is much smaller than that estimated from Table I.

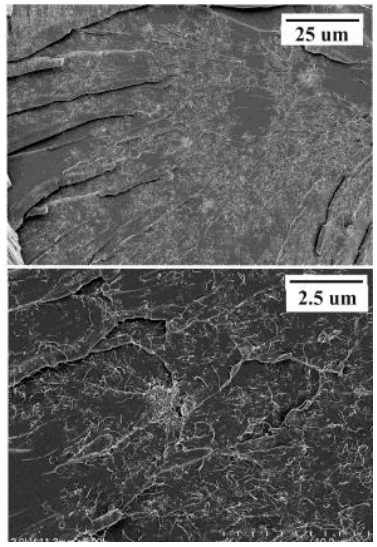

(a)

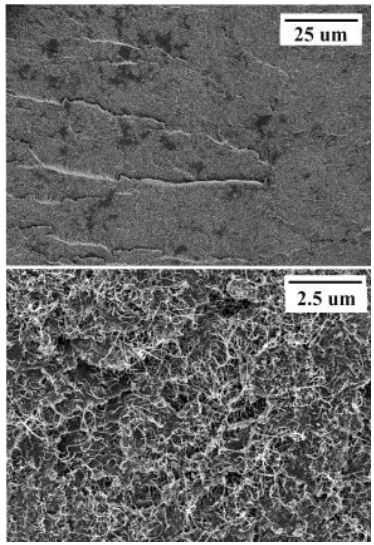

(b)
Fig. 1 SEM micrographs of NLIG composites (a) $1 w t \%$ loading, (b) $8 w t \%$ loading.

TABLE I

CHARACTERISTICS OF THE MWCNTS GIVEN BY THE MANUFACTURER

\begin{tabular}{|c|c|c|c|}
\hline Acronym & Lot no. & Outer Diam. (D)., nm & Length (L), um \\
\hline C100 & 7127 & $10-15$ & $0.1-10$ \\
\hline C150P & 103 & $13-16$ & $1->10$ \\
\hline NLIG & 43008 & $10-30$ & $5-20$ \\
\hline
\end{tabular}

TABLE II

MEASURED LENGTHS AND DIAMETERS OF THE MWCNTS

\begin{tabular}{|c|c|c|c|c|c|}
\hline \multicolumn{2}{|c|}{ MWCNT } & Min & Max & Mean & L/D \\
\hline \multirow{2}{*}{ NLIG } & L, um & 0.2 & 23.9 & 3.34 & \multirow{2}{*}{289.4} \\
\cline { 2 - 5 } & D, nm & 3.4 & 29.9 & 11.54 & \\
\hline \multirow{2}{*}{ C100 } & L, um & 0.1 & 4.5 & 0.91 & \multirow{2}{*}{71.4} \\
\cline { 2 - 5 } & D, nm & 5 & 27.5 & 12.74 & \\
\hline \multirow{2}{*}{ C150P } & L, um & 0.08 & 4.6 & 0.61 & \multirow{2}{*}{52.7} \\
\cline { 2 - 5 } & D, nm & 4.5 & 28.1 & 11.61 & \\
\hline
\end{tabular}

C. DC conductivity measurements and percolation curves

\section{Composite preparation}

The resin, the curing agent (26.4 wt\%) and the MWCNTs were weighed and hand mixed to form batches of $12 \mathrm{~g}$. As the reactivity of the curing agent is very low at room temperature, we added the curing agent from the beginning in order to reduce the mixture viscosity, especially for high nanotube loadings. The batch was three-roll-milled several times on a laboratory scale mill (EXAKT 80E, EXAKT Technologies, Inc.) at different shearing intensities. Next, the mixture was degassed in a vacuum oven at $90{ }^{\circ} \mathrm{C}$ for $30 \mathrm{~min}$ and loaded between two aluminum plates coated with demolding agent and separated by a PTFE spacer of $1.6 \mathrm{~mm}$ thickness. Finally, the plates were tightened together by bolt joints, and the composite was cured at $120^{\circ} \mathrm{C}$ for 6 hours. After demolding, the composite was trimmed to $50 \times 50 \mathrm{~mm}$ square with a thickness of $1.6 \mathrm{~mm}$. Batches with nanotube loading lower than $0.5 w t \%$ were prepared by dilution of the $0.5 w t \%$ mixture. The SEM micrographs of Fig. 1 show that three-roll milling is a very suitable method for homogeneously dispersing MWCNTs over a wide range of loadings.

\section{DC conductivity measurements}

The van-der-Pauw method [28] of measuring the conductivity of thin materials is widely used in the 
TABLE III

PERCOLATION PARAMETERS OF THE MWCNT SAMPLES

\begin{tabular}{|c|c|c|c|}
\hline MWCNT & $p_{c}, w t \%$ & $t$ & $\sigma_{0}, \mathrm{~S} / \mathrm{cm}$ \\
\hline NLIG & 0.012 & 1.77 & 230.75 \\
\hline C100 & 0.097 & 1.86 & 57.24 \\
\hline C150P & 0.188 & 1.96 & 39.81 \\
\hline
\end{tabular}

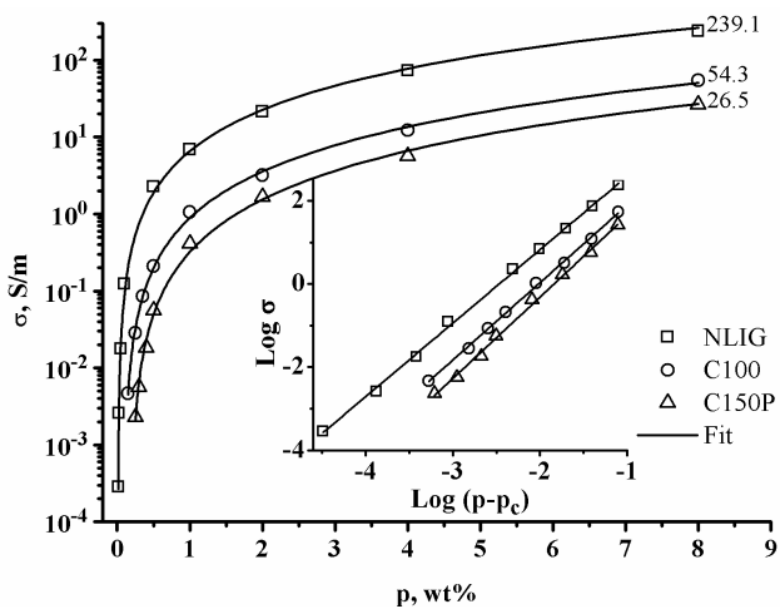

Fig. 2 Percolation curves of the considered MWCNTs, giving the DC conductivity as a function for the CNT loading.

semiconductor industry, and recently was used to assess the conductivity of CNT composites [29] at zero frequency or "DC". This four-probe method eliminates the contact resistance and only one accurate dimension (thickness) is needed to calculate the volume resistivity of the sample. The current source (Keithley 6220 DC) and the nanovoltmeter (Keithley 218A) were linked together and the measurements were done in delta mode, when the current source alternates the signal polarity and triggers the nanovoltmeter to read at each polarity. The accuracy of the measurement setup was verified using a conductivity standard of $111.1 \mathrm{~S} / \mathrm{m}$ (VLSI Standards Inc.).

\section{Percolation curves}

According to the statistical percolation theory the conductivity depends on the filler loading according to $[3,17]$

$$
\sigma=\sigma_{0}\left(p-p_{c}\right)^{t}
$$

where $p$ is nanotube weight fraction, $p_{c}$ is percolation threshold, $t$ is critical exponent and $\sigma_{0}$ is the conductivity of an element of the percolating network. It should be noted that we have used weight fractions instead of volume fractions as the densities of the investigated nanotubes. The percolation parameters were determined by iteratively varying $p_{c}$, until the best linear fit of $\log (\sigma)$ versus $\log \left(p-p_{c}\right)$ was obtained. Fig. 2 and Table III present the percolation curves and the percolation parameters respectively for our MWCNT samples.

It can be observed from Fig. 2 that the aspect ratio has an important influence on the conductivity. Thus composites with NLIG have conductivities almost 10 times higher than those with $\mathrm{C} 150 \mathrm{P}$, as the former has an aspect ratio 5.5 times greater then latter. The maximum conductivity of $239.1 \mathrm{~S} / \mathrm{m}$ obtained for NLIG at $8 w t \%$ is one of the highest values reported for epoxy-MWCNT composites at similar loading.

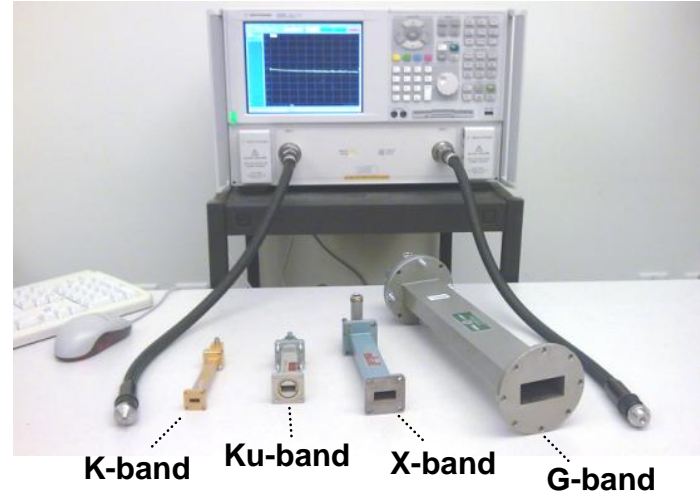

Fig. 3. G-, X-, Ku- and K-band waveguides with cables and network analyzer.

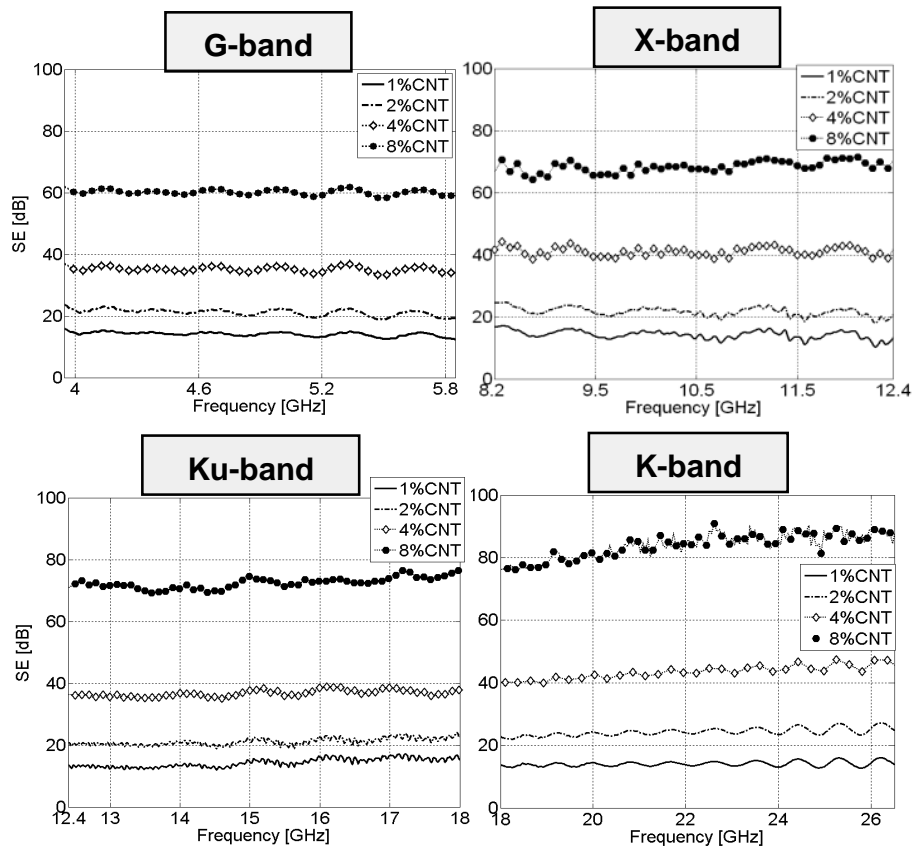

Fig. 4. Measured SE of NLIG samples over G-, X-, Ku- and K-band frequency ranges.

TABLE IV

SPECIFICATIONS OF TESTED NLIG SAMPLES

\begin{tabular}{c|c|c}
\hline $\begin{array}{c}\text { MWCNT } \\
(\% w t)\end{array}$ & $\begin{array}{c}\text { Volume fraction } \\
(\% v f)\end{array}$ & $\begin{array}{c}\text { Thickness }(d) \\
(\mathrm{mm})\end{array}$ \\
\hline 1 & 0.602 & 1.65 \\
\hline 2 & 1.210 & 1.67 \\
\hline 4 & 2.439 & 1.8 \\
\hline 8 & 4.959 & 1.9 \\
\hline
\end{tabular}

\section{SHIELDING EFFECTIVENESS OF MWCNT COMPOSITES}

The shielding effectiveness of our nanocomposites was experimentally investigated over a wide frequency range, up to $26.5 \mathrm{GHz}$, using rectangular waveguides. As shown in Fig. 3, we have used G-, X-, Ku- and K-band rectangular waveguides with dimensions of $47.548 \times 22.148 \mathrm{~mm}, 22.86 \times 10.16 \mathrm{~mm}$, $15.8 \times 7.9 \mathrm{~mm}$ and $10.668 \times 4.318 \mathrm{~mm}$, respectively. Using an Agilent-E8364B network analyzer, which can operate from 10 $\mathrm{MHz}$ to $50 \mathrm{GHz}$, the measured SE of NLIG samples with different MWCNT loading is presented in Fig. 4. The sample specifications are given in Table IV. The 


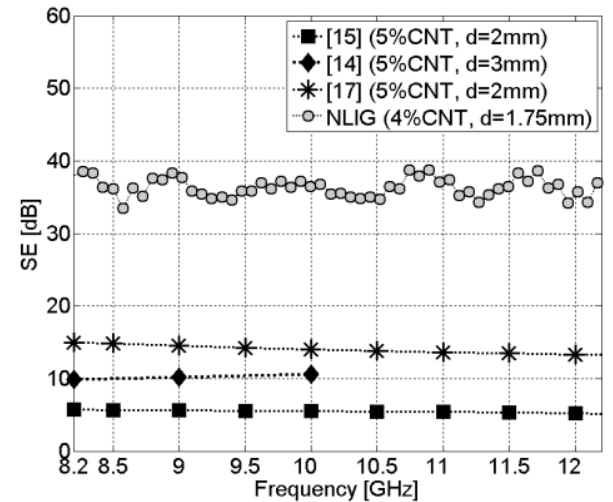

(a)

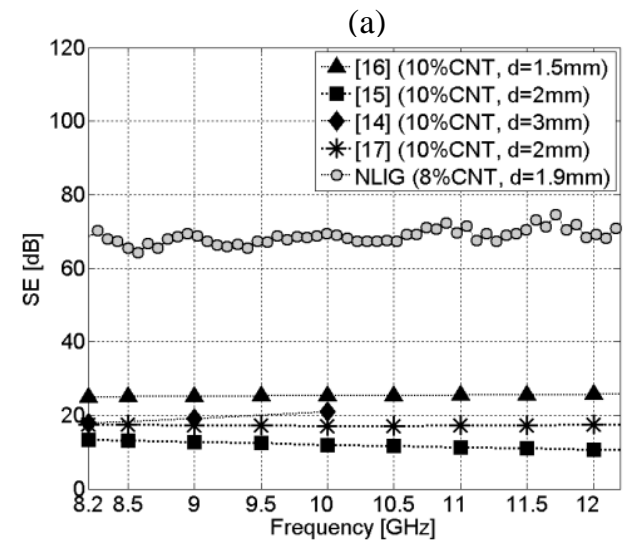

(b)

Fig. 5. Comparison of NLIG shielding performance with other samples from the literature: (a) 4\%wt and (b) $8 \%$ wt MWCNT NLIG.
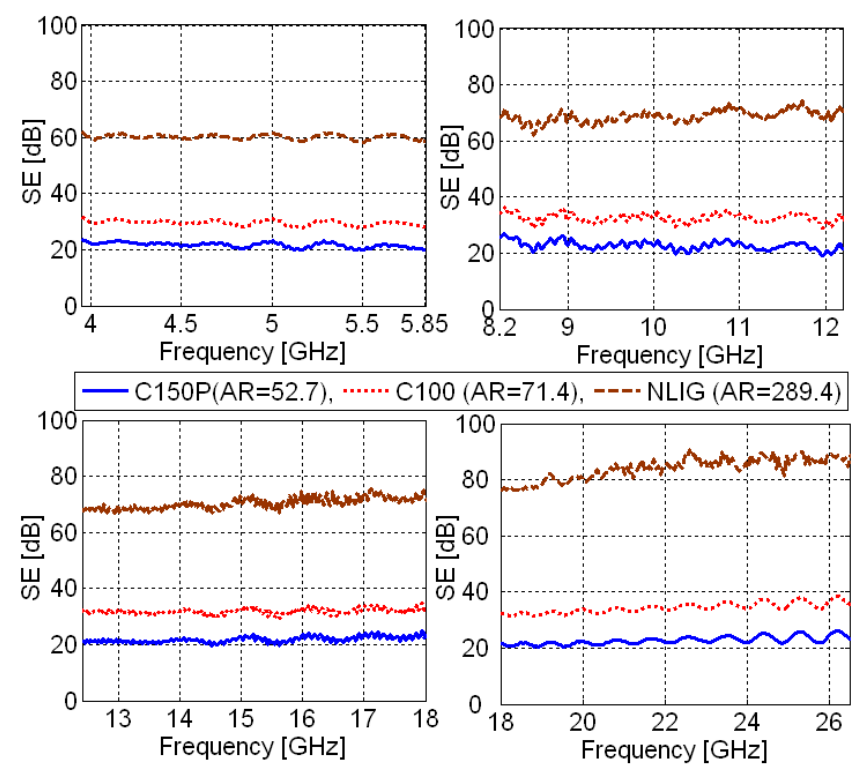

Fig. 6. The effect of aspect ratio on the SE of proposed $8 \% \mathrm{wt}$ nanocomposites.

SE is obtained by subtracting the measured $S_{21}$ of waveguide setup without sample from the $S_{21}$ when the sample is placed in the cross section of the waveguide. The SE increases from less than $20 \mathrm{~dB}$ for $1 \% w t$ to 20 to $25 \mathrm{~dB}$ for $2 \% w t, 35$ to $45 \mathrm{~dB}$ for $4 \% w t$ to 60 to $90 \mathrm{~dB}$ for $8 \% w t$. The SE is roughly constant with frequency at $\mathrm{G}$ and $\mathrm{X}$ band, and increases with

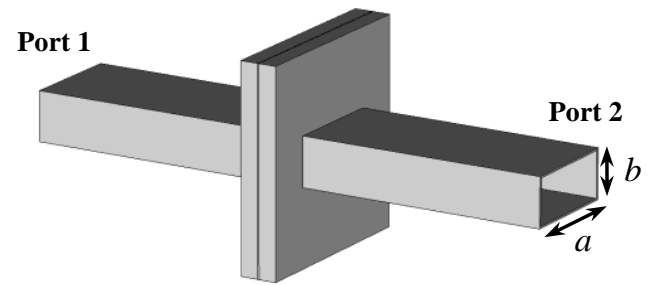

Fig. 7. The electromagnetic model of waveguide setup developed in CST MWS.

frequency at higher frequencies and higher CNT loadings, especially at $\mathrm{K}$ band up to $26.5 \mathrm{GHz}$. This behavior can be explained by the skin depth in the composite, which will be addressed in next section.

In Fig. 5 we have compared the shielding properties of our samples containing 4 and $8 \% w t$ NLIG with similar composites reported in the literature. It is observed that our nanocomposites based on NLIG with lower nanotube loading and smaller thickness have a much higher SE than those reported in [16-19]. It should be noted that the MWCNT samples reported in [16] are characterized over $8-10 \mathrm{GHz}$ frequency range so that the corresponding shielding performance in Fig. 5 is calculated only over that frequency band.

Fig. 6 presents the SE of nanocomposites made of MWCNTs with different aspect ratios (Table II). The MWCNT loading of these samples is $8 \%$ wt. The DC conductivity in Fig. 2 is strongly dependent on the aspect ratio. Fig. 6 shows that the SE is much higher using nanotubes with a high aspect ratio. Thus the SE with NLIG is 60 to $90 \mathrm{~dB}$ over the 4 to $26 \mathrm{GHz}$ frequency range, much larger than $\mathrm{C} 100$ which has an SE of 30 to $40 \mathrm{~dB}$.

\section{EFFECTIVE CONDUCTIVITY OF NLIG-MWCNT SAMPLES AND SIMULATION RESULTS}

In section II, D.C. conductivity $\left(\sigma_{D C}\right)$ of the nanocomposites was reported along with the percolation curves of Fig. 2. However, since composite materials may show a noticeable frequency-dependent behavior, it is important to characterize the effective parameters (conductivity, permittivity and permeability) of samples over high frequencies [16-20], [30, 31].

In this section, we have obtained the effective conductivity $\left(\sigma_{e f f}\right)$ of the nanocomposites by minimizing the difference between the measured scattering parameters, obtained from the waveguide setups, and the simulated scattering parameters using a model in CST MWS [16, 23]. The effective conductivity was also obtained by using analytical method and the results were compared with CST MWS results. Furthermore, for design purposes, the SE/thickness diagrams of $1 \%, 2 \%, 4 \%$ and $8 \%$ wt MWCNT NLIG samples are provided for the whole frequency range of interest.

\section{A. Effective Conductivity}

The scattering parameters of the slab of composite material sandwiched between waveguides as in Fig. 7 could be 


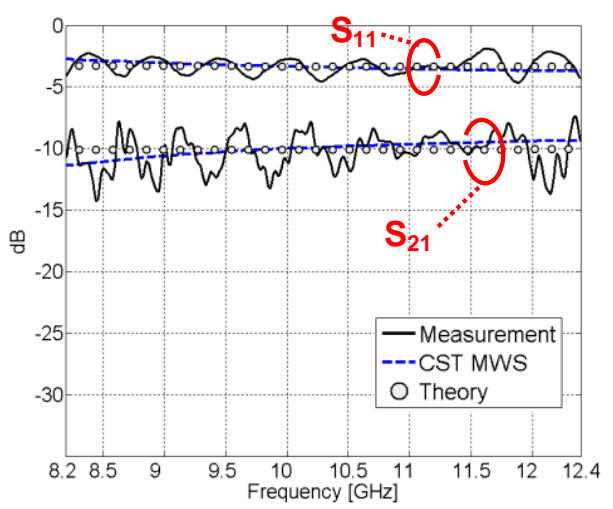

(a)

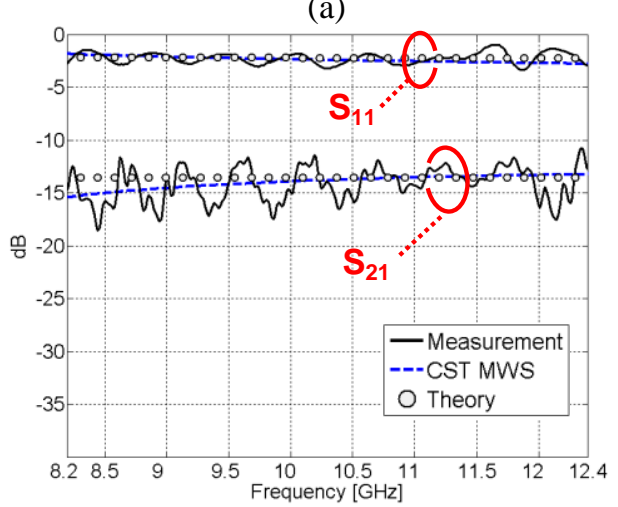

(b)

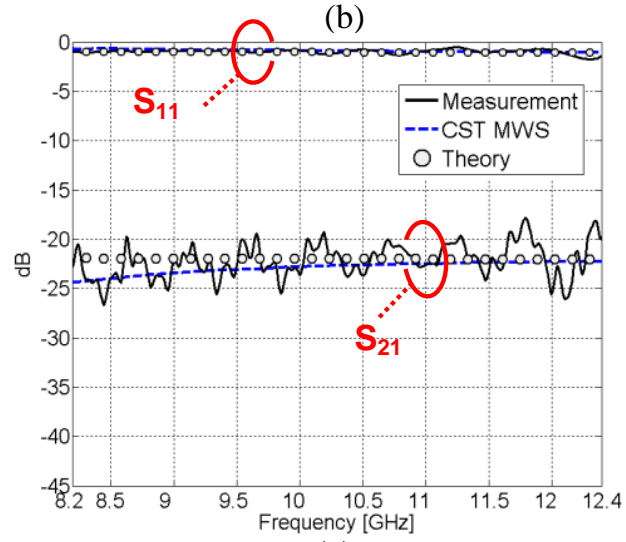

(c)

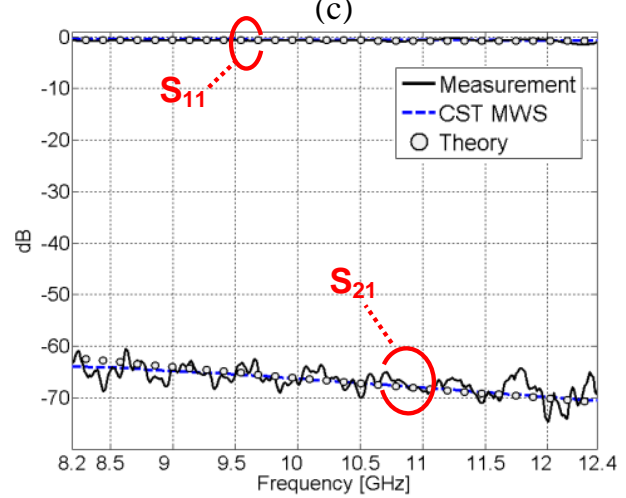

(d)

Fig. 8. The magnitude of scattering parameters of the proposed MWCNT nanocomposites, (a) $1 \% w t, d=0.9 \mathrm{~mm}$. (b) $2 \% w t, d=0.9 \mathrm{~mm}$, (c) $4 \% w t$, $d=0.5 \mathrm{~mm}$ and (d) $8 \% w t, d=2 \mathrm{~mm}$.

determined to high accuracy using mode matching [32], but here only the dominant mode will be accounted for. The slab

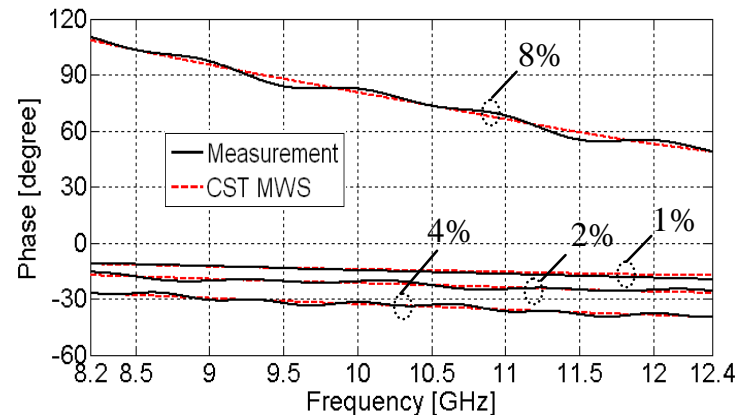

Fig. 9. The phase of $S_{21}$ parameter of the proposed MWCNT nanocomposites.

is assumed to have homogeneous effective parameters $\left(\varepsilon_{\text {reff }}\right.$, $\left.\mu_{\text {reff }}\right)$, where the complex permittivity is used to include the effect of loss. Our composite materials are non-magnetic so the permeability is that of free space $[16-20,30,31]$. The dominant mode inside the waveguide and slab is $\mathrm{TE}_{10}$ mode. Evanescent modes exist in the waveguide both inside the slab and in the air near the surfaces of the slab, and store energy. Based only on the dominant mode, the scattering parameters of the slab with thickness of $d$ in the waveguide are

$$
\begin{aligned}
S_{11} & =20 \log \left(\frac{E_{R}}{E_{i}}\right) \\
S_{21} & =20 \log \left(\frac{E_{T}}{E_{i}}\right)
\end{aligned}
$$

where

$$
\frac{E_{R}}{E_{i}}=\frac{r_{1}+r_{2} e^{-j 2 \beta_{T E 10} d}}{1+r_{1} r_{2} e^{-j 2 \beta_{T E 10} d}}
$$

and

$$
\frac{E_{T}}{E_{i}}=\frac{t_{1} t_{2} e^{-j \beta_{T E 10} d}}{1+t_{1} t_{2} e^{-j 2 \beta_{T E 10} d}}
$$

where $E_{i}, E_{R}$, and $E_{T}$ are incident, reflected and transmitted electric fields in the waveguide, respectively. The other parameters are

$$
\begin{gathered}
r_{1}=\frac{\sqrt{\mu_{\text {reff }} / \varepsilon_{\text {reff }}}-1}{\sqrt{\mu_{\text {reff }} / \varepsilon_{\text {reff }}}+1} \\
r_{2}=-r_{1} \\
\beta_{T E 10}=\sqrt{\omega^{2} \mu_{0} \mu_{r e f f} \varepsilon_{0} \varepsilon_{r e f f}-(\pi / a)^{2}}
\end{gathered}
$$

and

$$
\begin{aligned}
& t_{1}=\frac{2 \sqrt{\mu_{\text {reff }} / \varepsilon_{\text {reff }}}}{\sqrt{\mu_{\text {reff }} / \varepsilon_{\text {reff }}}+1} \\
& t_{2}=\frac{2}{\sqrt{\mu_{\text {reff }} / \varepsilon_{\text {reff }}}+1}
\end{aligned}
$$

and $\omega=2 \pi f$ and $a$ is the width of the waveguide. The accuracy of the model could be improved by accounting for higherorder modes, which are cutoff but which store energy.

Fig. 7 shows a realistic model of the waveguide measurement setup for analysis with CST MWS [33]. MWS is based on the finite integration technique (FIT), which 
TABLE V

EFFECTIVE RF CONDUCTIVITY OF NLIG SAMPLES VERSUS MWCNT CONCENTRATION

\begin{tabular}{|c|c|c|c|c|}
\hline \multirow{2}{*}{ Simulation Setup } & \multicolumn{4}{|c|}{ MWCNT (\% wt) } \\
\cline { 2 - 5 } & $\mathbf{1}$ & $\mathbf{2}$ & $\mathbf{4}$ & $\mathbf{8}$ \\
\hline CST MWS & $10 \mathrm{~S} / \mathrm{m}$ & $20 \mathrm{~S} / \mathrm{m}$ & $110 \mathrm{~S} / \mathrm{m}$ & $215 \mathrm{~S} / \mathrm{m}$ \\
\hline Analytical Model & $13 \mathrm{~S} / \mathrm{m}$ & $22 \mathrm{~S} / \mathrm{m}$ & $118 \mathrm{~S} / \mathrm{m}$ & $228 \mathrm{~S} / \mathrm{m}$ \\
\hline DC Measurement & $6.9 \mathrm{~S} / \mathrm{m}$ & $21.5 \mathrm{~S} / \mathrm{m}$ & $73.6 \mathrm{~S} / \mathrm{m}$ & $239.1 \mathrm{~S} / \mathrm{m}$ \\
\hline
\end{tabular}

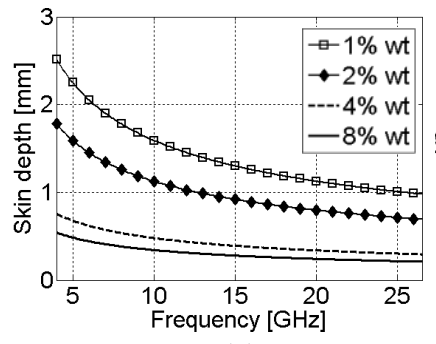

(a)

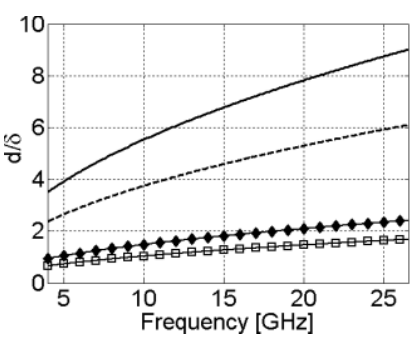

(b)
Fig. 10. (a) Skin depth of NLIG samples given in Table IV versus frequency, (b) Thickness to skin depth ratio of NLIG samples.

discretizes the integral form of Maxwell equations, and so inherently accounts for the energy-storage effects of cutoff waveguide modes in the slab and near the surfaces of the slab, and so is expected to be more accurate than the dominantmode analysis presented above.

In order to find the effective conductivity of the slab, we try to minimize the difference between measured and simulated $S_{11}$ and $S_{21}$ scattering parameters, for various complex permittivity values so that the conductivity can be extracted from the imaginary part of the complex permittivity. We match the mean value of the simulated scattering parameters to the mean value of the measured parameters over the desired frequency range, and choose the complex permittivity that makes the mean values closest. For conciseness, only the Xband results are reported as shown in Figures 8 and 9. The normalizing impedance used for the scattering parameters is $50 \Omega$. Table $\mathrm{V}$ shows the conductivity for samples with $1 \%$, $2 \%, 4 \%$ and $8 \%$ MWCNT, from both the CST MWS model and analytical model of (2) to (10). The conductivity values obtained by the two models are comparable, but differ somewhat. The more accurate values are those obtained by the MWS model, which inherently accounts for higher-order modes in the slab and near the surfaces of the slab. Table V shows also the measured DC conductivity of the samples. The values for $2 \%$ and $8 \%$ loading are comparable to the effective values determined from the MWS model, but the values for $1 \%$ and $4 \%$ loading are considerably different. The effective value $\varepsilon_{\text {reff }}$ for $1 \%, 2 \%, 4 \%$ and $8 \% w t$ samples is obtained as, $4,7,11$, and 15 , respectively. Due to the skin depth phenomenon, since for highly conductive materials the conductivity of material has major contribution in SE rather than relative permittivity, here we just discuss about the

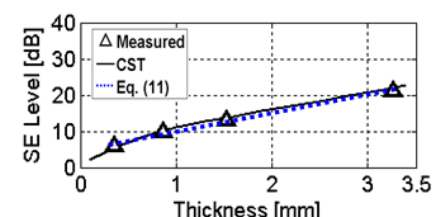

(a)

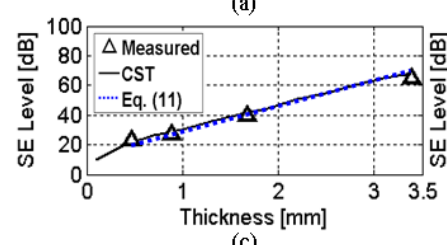

(c)

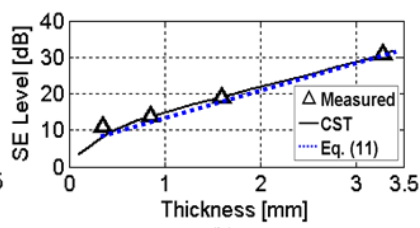

(b)



(d)
Fig. 11. The SE of NLIG sample versus sample thickness over X-band frequency range (a) $1 \%$, (b) $2 \%$, (c) $4 \%$, and (d) $8 \%$ loading.

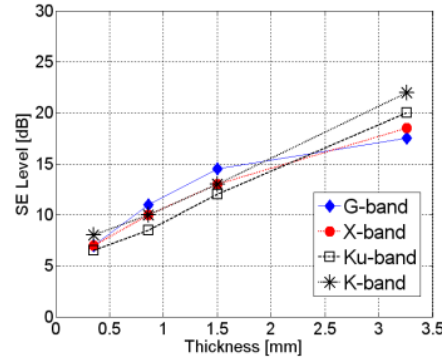

(a)

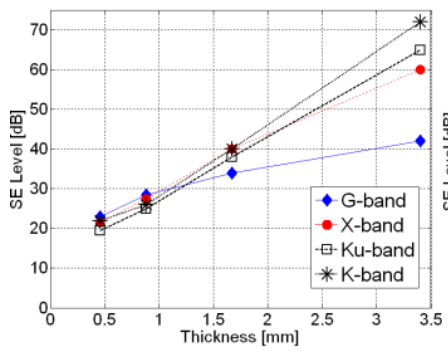

(c)

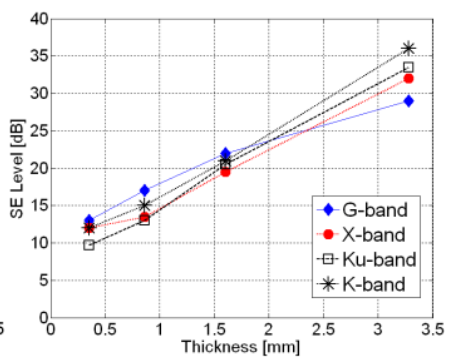

(b)

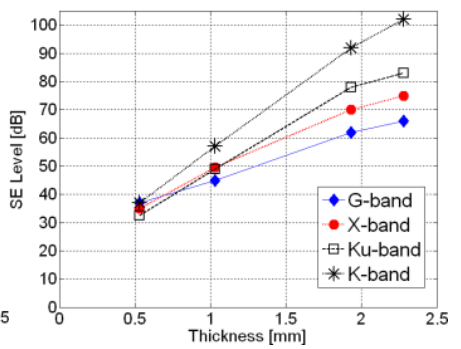

(d)
Fig. 12. Measured SE / Thickness of NLIG samples with different MWCNT loading: (a) $1 \%$, (b) $2 \%$, (c) $4 \%$, and (d) $8 \%$.

conductivity of samples. Fig. 10 (a) shows the skin depth, $\delta=1 / \sqrt{\pi f \mu_{0} \sigma}$, of the NLIG samples versus nanotube loading. Fig. 10(b) shows the ratio of sample thickness to skin depth $(d / \delta)$ for NLIG samples given in Table IV. It is observed that for NLIG with $8 \%$ wt loading, the thickness of samples in terms of the skin depth increases significantly with frequency. This explains why the SE in Fig. 4 increases with frequency between 18 and $26.5 \mathrm{GHz}$, where $d$ gets greater than about $8 \delta$. In fact, as the frequency increases, the skin depth decreases and the SE increases, even if the conductivity is constant.

\section{B. Effect of Sample Thickness on Shielding Properties}

For design purposes, we may need to control the shielding level by considering the cost limitations. It was observed that the level of SE could be controlled by using different MWCNT loadings. One of the important factors which can be used to adjust the level of SE is sample thickness. Therefore, providing the SE/thickness table for any kind of composite sample can be efficiently used for design purposes in different 
applications.

For a slab of conductive material where the skin depth is much less than the slab thickness, the SE can be estimated by ignoring interactions between the surfaces using [34]

$$
S E=20 \log \left|\frac{\left(\eta_{0}+\eta_{s}\right)^{2}}{4 \eta_{0} \eta_{s}}\right|+8.686\left(\frac{d}{\delta}\right)
$$

where $\eta_{s}$ and $\eta_{0}$ are the intrinsic impedances for the $\mathrm{TE}_{10}$ mode for the slab and for air, respectively and the SE is expressed in $\mathrm{dB}$. Equation (11) shows that the SE increases linearly with thickness $d$ for highly-conductive composite samples.

Using the waveguide setup simulated in CST MWS and using the effective parameters found in the previous section, we have investigated the effect of the sample thickness on SE of NLIG samples over the considered frequency range. Fig. 11 shows the simulated SE vs. thickness curves over X-band frequency range. By fabricating samples with different thicknesses, the experimental results (triangles in Fig. 11) are in good agreement with the simulations (solid line) and with (11) (dashed line). The SE of the composites shows a nearly linear dependence on the sample thickness with the slope given by (11). We also measured the level of SE for samples with different thicknesses over the G-, $\mathrm{X}-$, $\mathrm{Ku}$ - and $\mathrm{K}$ bands as shown in Fig. 12.

\section{CONCLUSIONS}

The length and diameter distribution of various massproduced MWCNTs from different providers have been successfully determined. While the average diameter was in good agreement with the manufacturer's specifications, the average length was significantly shorter. Three-roll milling was successfully used to form highly conductive homogeneous MWCNT-epoxy dispersions with nanotube loading up to 8 \%wt. The shielding performance of the proposed nanocomposites is investigated over a wide frequency range up to $26.5 \mathrm{GHz}$. The SE level can reach $90 \mathrm{~dB}$ in the K-band and more than $60 \mathrm{~dB}$ over G-, $\mathrm{X}$ - and Ku-band frequency ranges by loading sample with only $8 \% w t$ MWCNT. The proposed nanocomposites show much greater shielding effectiveness compared to the other types of CNT composites introduced in literature so far.

The effect of MWCNT aspect ratio is also investigated. It was found that higher aspect ratio results in lower percolation threshold and higher conductivity. An increase in the aspect ratio by a factor of 5.5 increases the $\mathrm{SE}$ of the corresponding composites by more than $40 \mathrm{~dB}$.

The effective conductivity of the proposed nanocomposites is calculated by fitting the simulated scattering parameters to the values measured using waveguide setups and conductivities as high as $228 \mathrm{~S} / \mathrm{m}$ are found. The effect of sample thickness on the shielding level of samples is investigated both numerically and experimentally over the frequency range of interest. It is found that as the thickness increases beyond several skin depths, the shielding effectiveness increases dramatically, and up to $90 \mathrm{~dB}$ of SE has been found for the composites in this paper.

Showing very high shielding effectiveness for low MWCNT loading $(<10 \%)$, nanocomposite made of long MWCNTs and epoxy resin is a good candidate for aerospace and aircraft industry.

\section{REFERENCES}

[1] D. Gay, and S. V. Hoa, Composite Materials, Design and Applications, 2nd ed. CRC press, 2007.

[2] A, Baker, S. Dutton, and D. Kelly, Composite Materials for Aircraft Structures, American Institute of Aeronautic and Astronautics Inc., 2004.

[3] W. Bauhofer, and J. Z. Kovacs, "A review and analysis of electrical percolation in carbon nanotube polymer composites", Compos. Sci. Technol. doi:10.1016/j. compscitech. 2008. $06.018,2008$.

[4] F. H. Gojny, M. H. G. Wichmann, B. Fiedler, I. A. Kinloch, W. Bauhofer, A. H. Windle, and K. Schulte, "Evaluation and identification of electrical and thermal conduction mechanisms in carbon nanotube/epoxy composites," Polymer, vol. 47, pp. 2036-2045, 2006.

[5] F. H. Gojny, M. H. G. Wichmann, B. Fiedler, and K. Schulte, "Influence of different carbon nanotubes on the mechanical properties of epoxy matrix composites - A comparative study," Compos. Sci. Technol., vol. 65, pp. 2300-2313, 2005.

[6] E. T. Thostenson, S. Ziaee, and T. W. Chou, "Processing and electrical properties of carbon nanotube /vinyl ester nanocomposites," Compos. Sci. Technol., doi:10.1016/j.compscitech.2008.06.023, 2008.

[7] E.T. Thostenson, and T.W. Chou, "Processing-structure-multifunctional property relationship in carbon nanotube/epoxy composites", Carbon, vol. 44, pp. 3022-9, 2006.

[8] J. Li, P. C. Ma, W. S. Chow, C. K. To, B. Z. Tang, and J. K. Kim, "Correlations between percolation threshold, dispersion state, and aspect ratio of carbon nanotubes," Adv. Funct. Mater., vol. 17, pp. 32073215, 2007.

[9] J. B. Bai, and A. Allaoui, "Effect of the length and the aggregate size of MWNTs on the improvement efficiency of the mechanical and electrical properties of nanocomposites-experimental investigation," Composites A, vol. 34, pp. 689-694, 2003.

[10] M. J. Jiang, Z. M. Dang, H. P. Xu, and S. H. Yao, "Effect of aspect ratio of multiwall carbon nanotubes on resistance-pressure sensitivity of rubber nanocomposites," Appl. Phys. Lett., vol. 91, pp. (072907) 1-3, 2007.

[11] C. M. Chang, M. C. Lin, J. C. Chiu, W. S. Jou, and W. H. Cheng, "High-Performance electromagnetic susceptibility of plastic transceiver modules using carbon nanotubes," IEEE Journal of Selected Topics Quantum Electronics, vol. 12, pp 1091-1096, 2006.

[12] C. M. Chang, J. C. Chiu, Y. F. Lan, J. W. Lin, C. Y. Yeh, W. S. Jou,.J. J. Lin, and W. H. Cheng, "High electromagnetic shielding of a 2.5-Gbps plastic transceiver module using dispersive multiwall carbon nanotubes", IEEE J. Lightwave Technology, vol. 26, pp. 1256-1262, 2008.

[13] W. S. Jou, H. Z. Cheng, and C. F. Hsua, "The electromagnetic shielding effectiveness of carbon nanotubes polymer composites," J. Alloys Compounds, vol. 434-435, pp. 641-645, 2007.

[14] H. M. Kim, K. Kim, S. J. Lee, J. Joo, H. S. Yoon, S. J. Cho, S. C. Lyu, and C. J. Lee, "Charge transport properties of composites of multiwalled carbon nanotube with metal catalyst and polymer: application to electromagnetic interference shielding," Current Applied Physics, vol. 4, pp. 577-580, 2004.

[15] C. S. Zhang, Q. Q. Ni, S.Y. Fu, and K. Kurashiki, "Electromagnetic interference shielding effect of nanocomposites with carbon nanotube and shape memory polymer," Comp. Sci. Technol., vol. 67, pp. 29732980, 2007.

[16] R. K. Challa, D. Kajfez, V. Demir, J. R. Gladden, and A. Z. Elsherbeni, "Characterization of multiwalled carbon nanotube (MWCNT) composites in a waveguide of square cross section," IEEE Microwave and Wireless Components Lett., vol. 18, no. 3, pp. 161-163, 2008.

[17] Z. Liu, G. Bai, Y. Huang, Y. Ma, F. Du, F. Li, T. Guo and Y. Chen, "Reflection and absorption contributions to the electromagnetic 
interference shielding of single-walled carbon nanotube/polyurethane composites," Carbon, vol. 45, pp. 821-827, 2007.

[18] Y. Li, C. Chen, S. Zhang,Y. Ni and J. Huang, "Electrical conductivity and electromagnetic interference shielding characteristics of multiwalled carbon nanotube filled polyacrylate composite films," Applied Surface Science, vol. 254, pp. 5766-5771, 2008.

[19] Y. Huang, N. Li, Y. Ma, F. Du, F. Li, X. He, X. Lin, H. Gao, and Y. Chen, "The influence of single-walled carbon nanotube structure on the electromagnetic interference shielding efficiency of its epoxy composites," Carbon, vol. 45, pp. 1614-1621, 2007.

[20] I. M. De Rosa, F. Sarasini, M. S. Sarto, and A. Tamburrano, "EMC impact of advanced carbon fiber/carbon nanotube reinforced composites for next-generation aerospace applications," IEEE Trans. Electromagn. Compat., vol. 50, pp. 556-563, 2008.

[21] P. C. Kim, and D. G. Lee, "Composite sandwich constructions for absorbing the electromagnetic waves," Composite Structures, vol. 87 pp. 161-167, 2009.

[22] K. Umishita, T. Okubo, N. Takuya, and O. Hashimoto, "Absorption and shielding effect of electromagnetic wave at $\mathrm{GHz}$ frequency by multiwalled carbon nanotube/polymer composites," Proc. of the 9th European Conf. on Wireless Tech., pp 291-294, 2006.

[23] A. Mehdipour, I. D. Rosca, A.-R. Sebak, C. W. Trueman, and S. V. Hoa, "Advanced carbon-fiber composite materials for RFID tag antenna applications", Applied Computational Electromagnetic Society (ACES) Journal, vol. 25, no. 3, pp. 218-229, 2010.

[24] A. Mehdipour, A.-R. Sebak, C. W. Trueman, I. D. Rosca, and S. V. Hoa, "Reinforced continuous carbon-fiber composites using multi-wall carbon nanotubes for wideband antenna applications," IEEE Trans. on Antenna and Propagat., vol. 58, no. 7, pp. 2451-2456, 2010.

[25] P. J Burke, and C. Rutherglen, "Carbon nanotube based variable frequency patch antenna", US patent 2009/0231205 A1, September 17, 2009.

[26] CONCORDIA CENTER FOR COMPOSITES (CONCOM), Concordia University, QC, Canada, 1979. Online: http://concom.encs.concordia.ca

[27] I. D. Rosca, and S. V. Hoa, "Highly conductive multiwall carbon nanotube and epoxy composites produced by three-roll milling," Carbon, vol. 47, pp. 1958-1968, 2009.

[28] L. J. van der Pauw, "A method of measuring the resistivity and Hall coefficient on lamellae of arbitrary shape," Phil. Tech. Rev., vol. 20, pp. 220-2244, 1958.

[29] J. Jang, J. Bae, and S. H. Yoon, "Study on the effect of surface treatment of carbon nanotubes for liquid crystalline epoxide-carbon nanotube composites," J. Mater. Chem., vol. 13, pp. 676-681, 2003.

[30] A. Balzano, I. M. De Rosa, F. Sarasini and M. S. Sarto, "Effective properties of carbon fiber composites: EM modeling versus experimental testing," Proc. of IEEE Int. Symp. EMC, Honolulu, HW, Jul. 2007.

[31] M. Koledintseva, P. C. Rawa, R. Dubroff, J. Drewniak, K. Rozanov and B. Archambeault, "Engineering of composite media for shields at microwave frequencies," Proc. of IEEE Int. Symp. EMC, vol. 1, 2005, pp. 169-174.

[32] T. Itoh, Numerical techniques for microwave and millimeter-wave passive structure, Chapter 9, John Wiley and Sons, 1989.

[33] Computer Simulation Technology. (2008), [Online] Available: http://www.cst.com.

[34] C. R. Paul, Introduction to Electromagnetic Compatibility, Wiley Series in Microwave and Optical Engineering, 1992



Aidin Mehdipour received the B.S. degree from Amirkabir University of Technology, Tehran, Iran, in 2003, the M.S. degree from the University of Tehran, Tehran, Iran, in 2006, and the Ph.D. degree from Concordia University, Montreal, QC, Canada, in 2011, all in electrical engineering. He is currently a Postdoctoral Fellow with the Institute National de la Recherche Scientifique (INRS), Montreal, QC, Canada. His main research interests include advanced carbon fiber composites, novel material development for shielding and antenna/microwave applications, EMI/EMC, small antenna design, RFID, multiband, ultrawideband, and millimeter wave antennas.

Dr. Mehdipour has won several prestigious awards such as the Governor General's Gold Medal-Technology, Industry and the Environment, awarded by the government of Canada, and David J. Azrieli Graduate Fellowship, as the highest ranking fellowship award in Concordia University. He was awarded the France and André Desmarais Graduate Fellowship in 2010, the Howard Webster Foundation Doctoral Fellowship and Doctoral Thesis Completion Award in 2011. He is a member of IEEE AP and EMC societies and of the Applied Computational Electromagnetics Society (ACES).

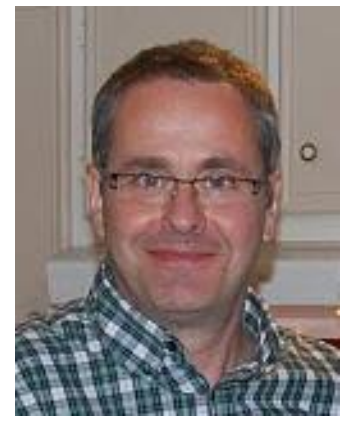

Iosif Daniel Rosca received his engineer diploma in Polymer Science and Technology from Polytechnic University of Bucharest, Romania. He earned his Ph.D. in Chemistry with Prof. J.M. Vergnaud at Jean Monnet University, Saint-Etienne, France. Rosca spent 2 years as JSPS Postdoctoral Fellow at Hokkaido University, Japan. $\mathrm{He}$ is currently a Research Associate with Prof. S.V. Hoa at Concordia University, Canada. His present research focuses on fabrication and application of polymer composites based

on carbon nanomaterials.

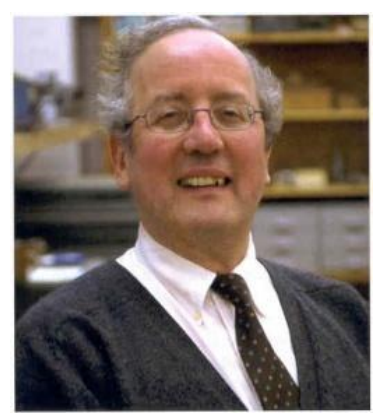

Christopher W. Trueman received his Ph.D. from McGill University in 1979. He has applied the methods of computational electromagnetics to problems such as aircraft antenna performance, antenna-to-antenna coupling and EMC on aircraft, aircraft and ship radar cross-section at $\mathrm{HF}$ frequencies, suppression of scattering of the signal of a commercial radio station from power lines, dielectric resonators, unconditionally-stable formulations for the finite-difference time-domain method, and the fields of portable radios such as cellular phones held against the head. Recently, his research has investigated carbon composite materials for aircraft and for building antennas, indoor propagation, and EMC issues between portable radios and medical equipment. Dr. Trueman is currently the Associate Dean for Academic Affairs in the Faculty of Engineering and Computer Science at Concordia University. 


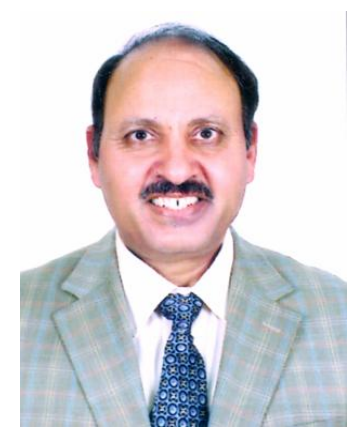

Abdel R. Sebak received the B.Sc. degree from Cairo University, the M.Eng. and Ph.D. degrees from the University of Manitoba all in electrical engineering.

From 1984 to 1986, he was with the Canadian Marconi Company working on the design of microstrip phased array antennas. From 1987 to 2002, he was a Professor in the ECE Department, University of Manitoba. $\mathrm{He}$ is a Professor of Electrical and Computer Engineering, Concordia University, Montreal. His current research interests include phased array antennas, mm-wave imaging, computational electromagnetics, and interaction of EM waves with new materials and bio-electromagnetics.

Dr. Sebak received the 2000 and 1992 University of Manitoba Merit Award for outstanding Teaching and Research, the $1994 \mathrm{Rh}$ Award for Outstanding Contributions to Scholarship and Research, and the 1996 Faculty of Engineering Superior Academic Performance. Dr. Sebak has served as Chair for the IEEE Canada Awards and Recognition Committee (2002-2004) and the Technical Program Chair ANTEM-2006.

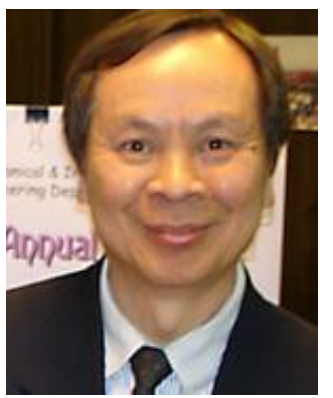

Suong Van Hoa obtained his Bachelor of Engineering from University of California, San Luis Obispo in 1971, Master of Applied Science (1973) and Ph.D ( 1976) from University of Toronto, all in Mechanical Engineering. After graduation, he was working as a design engineer at Canadian Fram Ltd. in Chatham, Ontario from 1976 till 1977 when he joined the department of Mechanical Engineering at Concordia University as an Assistant professor. Dr. Suong V. Hoa has been a full professor at the Department of Mechanical and Industrial Engineering at Concordia University, Montreal, Quebec, Canada since 1986. He was also Chair of the Department for 9 years from 1994-2000 and 2003-2006. He has been working on Composites for the past 32 years (since 1979). He established the Concordia Center for Composites at Concordia university from 1993 and has been Director of the Center since. He was recognized as Concordia University research fellow in 2001. He has been appointed Concordia University research chair from 2011 until 2015. Dr. Hoa is Fellow of the American Society of Mechanical Engineers since 1996, Fellow of the Canadian Society for Mechanical Engineering since 1996, Fellow of the Engineering Institute of Canada since 1997. Dr. Hoa founded the Canadian Association for Composite Structures and Materials (CACSMA) in 1988. He received the Synergy award for collaborative work on composites with Bell Helicopter from the Natural Sciences and Engineering Research Council of Canada in 2006. He also received the Prix partenariat from Association des Directeur de Recherche Industrielle du Quebec in 2006 and in 2009. Dr. Hoa is the recipient of the Nano Academia prize from Nanoquebec in 2008. He was given the title of Research Fellow from Pratt \& Whitney Canada Ltd. in September 2008. He together with Dr. H. Hamada of Kyoto Institute of Technology, initiated the series of Canada-Japan workshop on composites which have been held in Canada and Japan every two years since 1996. Dr. Hoa has supervised to graduation 66 graduate students. He has written 6 books and close to 500 publications in scientific journals and conference proceedings. $\mathrm{He}$ has worked with many companies and organizations in Canada and in other countries. He has organized close to 20 international conferences on composite, including the International Conference on Composite Materials, ICCM19, in Montreal in 2013. 